\title{
Editorial
}

\section{Twenty Five Years of the IPCC Reports}

$\mathrm{B}_{\mathrm{r}}$ ack in the 1980s the World Meteorological Organization and the United Nations Environment Program both concluded that the emerging evidence for global change driven by human emissions of greenhouse gases was alarming, pervasive and yet politically ignored. What was needed was a high level body to bring the data together and provide a dispassionate scientific account of what was happening to the world's climate. They determined to establish the Intergovernmental Panel on Climate Change (IPCC) as the driver for gathering and assessing the evidence and publishing periodic reports.

Created in 1988, the initial members acted with speed to provide, in 1990, the First Assessment Report of the IPCC, a key document for negotiating the United Nations Framework Convention on Climate Change (UNFCCC). In 1992, at the Earth Summit, UNFCCC was opened for signature and came into force in 1994. In 1995, the first Conference of the Parties (COP) took place in Berlin using the IPCC Second Assessment as the basis for discussions. Last year, the Fifth Assessment was finalized and is to be used as the basis for discussions at the COP in December 2015 in Paris.

The five assessment reports published by Cambridge University Press have sold over 160000 copies and spawned a wide range of complementary books in many languages explaining the evidence in a variety of ways. They have also triggered a predictable backlash from some in business, especially energy companies, who see the evidence as a potential attack on their profits, and also from extreme right wing politicians.

What has been achieved by the Scientific Committee of the IPCC since 1988? Firstly, it has grown from a fragmented group of scientists concerned about global change to an organized, critical and focused system that now comprises almost all the leading climate scientists world wide as well as many from other disciplines who have been alarmed at the impacts of change. Secondly, it has developed a robust system for trawling the world science literature and rigorously assessing the specific and collective significance of published science. Thirdly, it has devised a risk assessment system - now widely copied - in which panels provide a balanced view of the likelihood of a particular statement, making its conclusions much more useful to policy makers. Fourthly, it has maintained its activities separate from the politics associated with such a contentious topic, attempting at each stage to provide evidence that is policy-relevant but not policy-prescriptive. Indeed, the relationship between the UNFCCC and the IPCC has become a model for interaction between science and decision makers.

For the Fifth Assessment there were 830 lead authors and review editors selected from 3598 experts (nominated by 85 countries) and thousands of others involved in generating over 142,000 comments during review. There is a regular turnover of membership with $63 \%$ of the present group being directly involved for the first time. This surely has to be one of the most rigorous preparations of scientific data for policy use that has ever been devised. Of course, since governments are involved in the approval of the summary products, there are those who say the system is politicized. And the nay-sayers continue to deny the evidence and suggest conspiracy amongst the science community.

The conspiracy is amongst those who see profit as more important than survival, ignorance as preferable to understanding. Here, we should celebrate the development of the IPCC as a practical system to assess scientific evidence that is robust enough to withstand attack from the multinationals and ideologues, and inclusive enough to encompass scientists from almost half the countries of the world in a collaborative process for everyone's benefit. And it might even make a difference to all our futures!

D.W.H. WALTON 